\title{
Unmet Needs for Ancillary Services Among Men Who Have Sex with Men and Who Are Receiving HIV Medical Care — United States, 2013-2014
}

\author{
Nicholas P. DeGroote, MPH ${ }^{1,2}$; Lauren C. Korhonen, MSPH ${ }^{1,2}$; R. Luke Shouse, MD ${ }^{1}$; Linda A. Valleroy, $\mathrm{PhD}^{1}$; Heather Bradley, PhD ${ }^{1}$
}

Gay, bisexual, and other men who have sex with men (MSM) are disproportionately affected by human immunodeficiency virus (HIV) in the United States (1). Ancillary services, defined as services that support retention in HIV medical care and assist with day-to-day living, can improve the health of HIVinfected MSM and help them achieve viral suppression (2). To assess the unmet needs for ancillary services among MSM receiving outpatient HIV medical care during 2013-2014, CDC used data from the Medical Monitoring Project (MMP), a surveillance system designed to assess clinical and behavioral characteristics of adults receiving HIV care, to obtain nationally representative estimates of, and identify reasons for, unmet needs (3). Based on self-reported needs of persons responding to the MMP survey, the most prevalent unmet needs were for non-HIV medical care services: approximately $23 \%$ had an unmet need for dental care, and 19\% had an unmet need for eye or vision care. Unmet needs were most prevalent among young, non-Hispanic black, and Hispanic/Latino MSM. State and local health departments, community-based organizations, and health care providers might improve the health of MSM living with HIV by promoting access to ancillary services using strategies that increase patient awareness of how to obtain these services, especially among young, non-Hispanic black, and Hispanic/Latino MSM.

Data from MMP were used to estimate prevalence of unmet needs for ancillary services among MSM receiving outpatient HIV medical care during 2013-2014. MMP used a threestage sample (states and territories, facilities, and patients) and response rates at each stage were 100\% (states and territories), $85 \%$ (facilities) and 55\% (patients). Data were collected using face-to-face or telephone interviews during June 2013May 2015. Data were weighted for unequal selection probabilities and nonresponse (3).

MSM were defined as men who reported sex with one or more men during the 12 months preceding the interview, or if no sexual activity was reported, men who self-identified as homosexual, gay, or bisexual. Unmet needs were defined as services that participants reported needing, but not receiving, during the 12 months preceding the interview. Unmet needs for MSM overall and, for selected services, stratified by age and race/ethnicity, were estimated using chi-square tests to make statistical comparisons between strata. Services were selected for further analysis based on the frequency that services were reported as unmet needs in this survey and in previous studies.
For each of these services, participants' primary reasons for unmet needs were described.

Among MSM receiving outpatient HIV medical care in the United States, the most prevalent unmet needs were for non-HIV medical care services: $23 \%$ had an unmet need for dental care, and $19 \%$ had an unmet need for eye or vision care. In addition, $6 \%$ had an unmet need for mental health care (Figure). Among HIV support services examined, the most prevalent unmet need was for HIV peer group support (8\%). Among subsistence services, the most prevalent unmet need was for food or nutrition services (12\%). Seven percent had an unmet need for transportation assistance, and $7 \%$ had an unmet need for shelter or housing services.

MSM aged 18-29 years, 30-39 years, and 40-49 years had higher prevalences of unmet need for dental care, shelter and housing, and food or nutrition services compared with MSM aged $\geq 50$ years (Table 1 ). MSM aged 30-39 years and 40-49 years also had higher prevalences of unmet need for eye or vision care and mental health care. Non-Hispanic black MSM had higher prevalences of unmet need for dental care $(27 \%)$, transportation assistance $(9 \%)$, shelter or housing (10\%), and food or nutrition services (14\%) compared with non-Hispanic white MSM (20\%, 6\%, 5\%, and 10\%, respectively). Hispanic/Latino MSM had higher prevalences of unmet need for shelter or housing $(8 \%)$ and food or nutrition services (14\%).

Approximately $40 \%$ of MSM with an unmet need for HIV peer group support, transportation assistance, or food or nutrition services did not know how to get these services (Table 2). Twenty-two percent of MSM with an unmet need for mental health care did not know how to obtain care, and 25\% had psychological barriers preventing them from obtaining care. Approximately one quarter of MSM with an unmet need for either dental care or eye or vision care did not receive these services because of money (25\%) or health insurance issues (28\%). Twenty percent of MSM with an unmet need for shelter or housing services, $15 \%$ with an unmet need for transportation assistance, and 14\% with an unmet need for food or nutrition services were ineligible for, perceived themselves to be ineligible for, or were denied these services.

\section{Discussion}

MSM in HIV medical care in the United States had substantial unmet needs for ancillary services during 2013-2014. 
FIGURE. Unmet and met needs for ancillary services* among men who have sex with men and are receiving outpatient HIV medical care Medical Monitoring Project, United States, 2013-2014

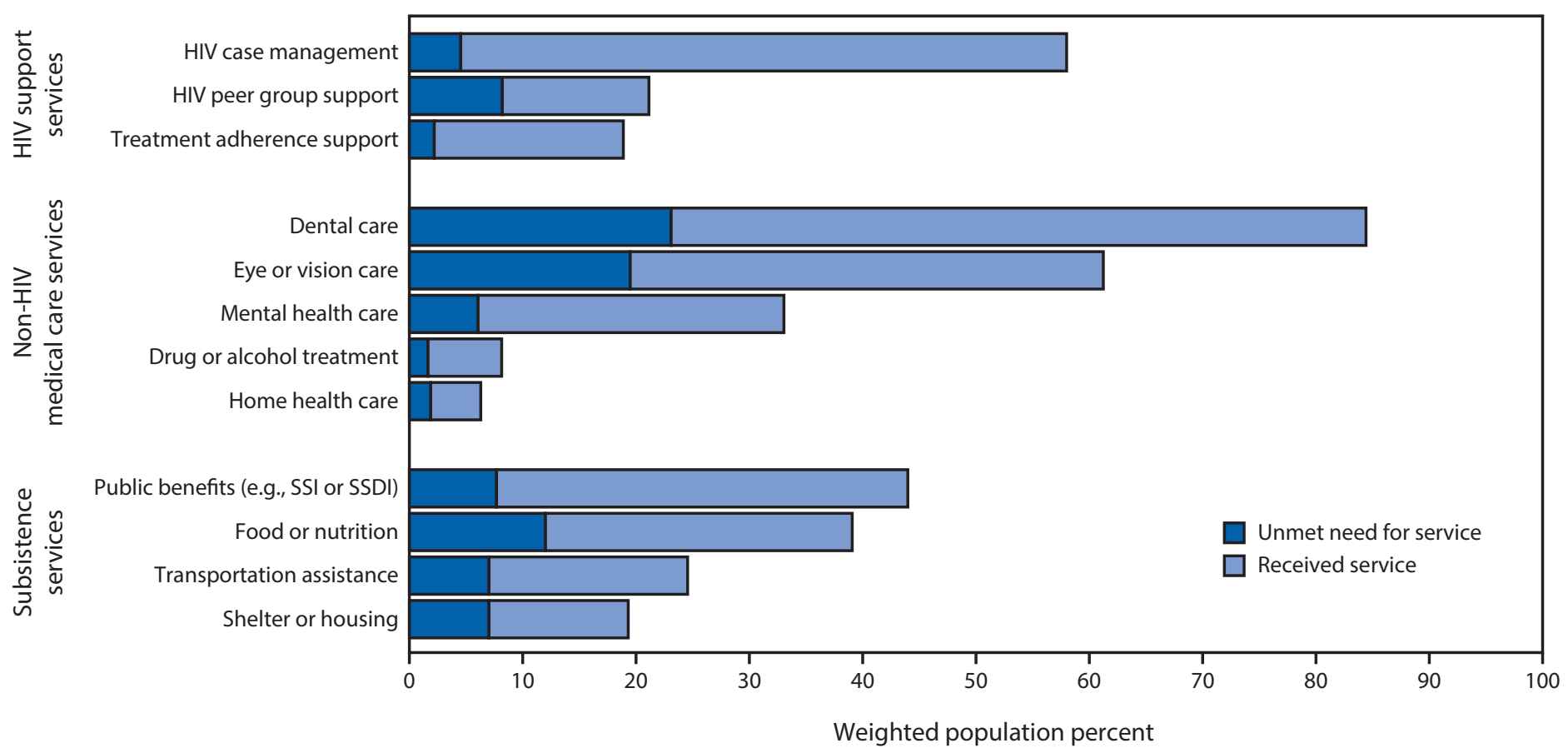

Abbreviations: HIV = human immunodeficiency virus; SSI = Supplemental Security Income; SSDI = Social Security Disability Insurance.

* Ancillary services are defined as services that support retention in primary HIV medical care and assist with day-to-day living.

TABLE 1. Percentage of men who have sex with men and who are receiving outpatient HIV medical care with unmet needs for ancillary services,* by demographic characteristics — Medical Monitoring Project, United States, 2013-2014

\begin{tabular}{|c|c|c|c|c|c|c|c|c|}
\hline \multirow[b]{2}{*}{$\begin{array}{l}\text { Demographic } \\
\text { characteristic }\end{array}$} & \multirow[b]{2}{*}{ Total no. } & \multicolumn{7}{|c|}{ Ancillary service $\%^{\dagger}\left(95 \% \mathrm{Cl}^{\S}\right)$} \\
\hline & & Dental care & $\begin{array}{l}\text { Eye or } \\
\text { vision care }\end{array}$ & $\begin{array}{c}\text { HIV peer } \\
\text { group support }\end{array}$ & $\begin{array}{l}\text { Transportation } \\
\text { assistance }\end{array}$ & $\begin{array}{l}\text { Shelter or } \\
\text { housing }\end{array}$ & $\begin{array}{l}\text { Food or } \\
\text { nutrition }\end{array}$ & $\begin{array}{c}\text { Mental } \\
\text { health care }\end{array}$ \\
\hline \multicolumn{9}{|l|}{ Age group (yrs) } \\
\hline $18-29$ & 534 & $31^{\text {ศ }}(25-37)$ & $19(16-22)$ & $9^{9}(7-12)$ & $7(5-10)$ & $14^{\pi}(10-18)$ & $15^{\natural}(11-19)$ & $6(4-8)$ \\
\hline $30-39$ & 828 & 29 ( $24-33)$ & $21^{9}(17-25)$ & $9(7-12)$ & 9ी $(6-11)$ & $10^{\natural}(8-12)$ & 16 (12-19) & $8^{9}(5-10)$ \\
\hline $40-49$ & 1,395 & $23^{9}(20-27)$ & $22^{\text {甲 }}(19-25)$ & $9(6-11)$ & $7(6-9)$ & 7 (5-8) & $12^{9}(10-15)$ & $7^{9}(6-8)$ \\
\hline$\geq 50$ & 2,005 & $18(15-21)$ & $17(16-19)$ & $7(6-9)$ & $6(5-7)$ & $4(3-5)$ & $9(8-11)$ & $5(4-6)$ \\
\hline \multicolumn{9}{|l|}{ Race/Ethnicity** } \\
\hline White, non-Hispanic & 2,203 & $20(15-24)$ & $19(16-22)$ & $8(6-10)$ & $6(4-8)$ & $5(4-5)$ & $10(7-12)$ & $6(4-7)$ \\
\hline Black, non-Hispanic & 1,247 & $27^{+\dagger}(24-30)$ & $19(16-22)$ & $7(5-9)$ & $9^{\dagger \dagger}(7-11)$ & $10^{+\dagger}(8-12)$ & $14^{+\dagger}(13-16)$ & $6(4-8)$ \\
\hline Hispanic or Latino & 1,072 & $25(21-28)$ & $22(19-24)$ & $9(7-11)$ & $8(6-9)$ & $8^{+\dagger}(6-11)$ & $14^{+\dagger}(12-17)$ & $7(5-9)$ \\
\hline Other $\S^{\S}$ & 240 & $26^{+\dagger}(22-31)$ & $20(15-25)$ & $13^{++}(8-17)$ & $7(4-10)$ & $9^{++}(5-12)$ & $11(6-16)$ & $7(5-9)$ \\
\hline Total & & $23(20-26)$ & $19(18-21)$ & $8(7-10)$ & $7(6-8)$ & $7(6-8)$ & $12(11-14)$ & $6(5-7)$ \\
\hline
\end{tabular}

Abbreviations: $\mathrm{Cl}=$ confidence interval; $\mathrm{HIV}=$ human immunodeficiency virus.

* Ancillary services are defined as services that support retention in primary HIV medical care and assist with day-to-day living.

† Percentages are weighted percentages.

$\S \mathrm{Cls}$ incorporate weighted percentages.

I $p$-value $<0.05$ in comparison to reference group (aged $\geq 50$ years).

** Race/ethnicity groups are mutually exclusive. Hispanics or Latinos could be of any race.

${ }^{+\dagger} \mathrm{p}$-value $<0.05$ in comparison to reference group (non-Hispanic white).

$\S \S$ Includes American Indian/Alaska Native, Asian, Native Hawaiian/Other Pacific Islander, or multiple races.

The most prevalent unmet needs were for dental care and eye or vision care, which are essential because many persons living with HIV have oral or eye conditions (e.g., candidiasis, Kaposi's sarcoma) that require specialized care. Unmet needs were also identified for services that help persons living with
HIV stay in medical care and adhere to HIV treatment. Young, non-Hispanic black, and Hispanic/Latino MSM had the most unmet needs for ancillary services. Many of the reasons MSM have unmet needs for ancillary services 
Morbidity and Mortality Weekly Report

TABLE 2. Reasons for unmet needs for ancillary services* among men who have sex with men and who are receiving outpatient HIV medical care - Medical Monitoring Project, United States, 2013-2014

\begin{tabular}{|c|c|c|c|c|c|c|}
\hline \multirow[b]{2}{*}{ Service } & \multirow[b]{2}{*}{ Total no. } & \multicolumn{5}{|c|}{ Reason for unmet needs $\%^{\dagger}\left(95 \% \mathrm{Cl}^{\S}\right)$} \\
\hline & & $\begin{array}{l}\text { Didn't know how } \\
\text { to get service }\end{array}$ & $\begin{array}{l}\text { In process of } \\
\text { getting service }\end{array}$ & $\begin{array}{l}\text { Not eligible or } \\
\text { denied services }\end{array}$ & $\begin{array}{c}\text { Money or } \\
\text { insurance issues }\end{array}$ & $\begin{array}{l}\text { Psychological } \\
\text { barriers }\end{array}$ \\
\hline Dental care & 1,099 & $14(12-16)$ & $26(22-31)$ & $6(4-8)$ & $25(21-29)$ & $12(8-16)$ \\
\hline Eye or vision care & 957 & $19(17-22)$ & $28(22-33)$ & $5(3-7)$ & $28(23-32)$ & $8(4-12)$ \\
\hline HIV peer group support & 387 & $41(35-47)$ & $6(3-9)$ & ๆ $(-)$ & ๆ $(-)$ & $14(10-17)$ \\
\hline Transportation assistance & 348 & $45(40-49)$ & $8(5-11)$ & $15(11-19)$ & १(-) & ๆ $(-)$ \\
\hline Shelter or housing & 336 & $3123-39$ & $20(14-26)$ & $20(16-23)$ & 9 (-) & 9 $(-)$ \\
\hline Food or nutrition & 597 & $41(37-45)$ & $13(9-16)$ & $14(10-19)$ & १ (-) & $7(4-10)$ \\
\hline Mental health care & 286 & $22(16-27)$ & $16(12-20)$ & $5(2-8)$ & $13(9-17)$ & $25(19-32)$ \\
\hline
\end{tabular}

Abbreviations: $\mathrm{Cl}=$ confidence interval; $\mathrm{HIV}=$ human immunodeficiency virus.

* Ancillary services are defined as services that support retention in primary HIV medical care and assist with day-to-day living.

† Percentages are weighted percentages.

$\S$ Cls incorporate weighted percentages.

ๆ Estimates suppressed because coefficient of variation for the estimate was $\geq 30 \%$.

resulted from inadequate knowledge or insufficient resources for obtaining services.

Many persons living with HIV in the United States lack basic life necessities (2). Among persons in HIV medical care, approximately half have household incomes at or below the poverty threshold (3), $18 \%$ are uninsured (4), and $8 \%$ are homeless (3). For persons in need, ancillary services, including food or nutrition, transportation assistance, and shelter or housing, are fundamental for accessing medical care, adhering to HIV treatment, and being virally suppressed (2).

In 2014, most MSM with newly diagnosed HIV were young, non-Hispanic black, or Hispanic/Latino (1). Among MSM with diagnosed HIV, these populations have the lowest levels of antiretroviral therapy use and viral suppression (5), as well as substantial unmet needs for ancillary services. Improving access to ancillary services that facilitate HIV care and improved treatment outcomes might help reduce age and racial/ethnic disparities in HIV-related health outcomes and ongoing HIV transmission.

Reducing unmet needs for ancillary services among MSM living with HIV could help accelerate progress toward reaching the National HIV/AIDS Strategy goal of increasing access to care and improving health outcomes for persons living with HIV. This strategy specifies goals for improving health outcomes among persons living with HIV by increasing access to basic needs $(\sigma)$ and focuses on increasing stable housing for persons living with HIV, which has consistently been shown to support retention in HIV care and HIV treatment adherence ( 7 ).

The Ryan White HIV/AIDS Program is the primary funder of ancillary services for persons living with HIV in the United States through grants to states, territories, and communitybased organizations that serve approximately half a million persons each year (8). A previous study found that $73 \%$ of persons in HIV care received services from clinics funded by the Ryan White program; among those, 32\% received meal or food services, $29 \%$ received transportation assistance, and $18 \%$ received shelter or housing services, compared with $21 \%$, $16 \%$, and $10 \%$, respectively, of persons in HIV care in clinics not funded by the program (9).

Findings from this analysis indicate some MSM were not accessing ancillary services because they did not know how to get services, were not eligible or were denied services, or had psychological barriers. Co-locating ancillary services with routine HIV medical care using a medical home model is a hallmark of the Ryan White HIV/AIDS Program (10). Expansion of the medical home model for HIV care by health departments, health care providers, and community-based organizations would likely increase access to needed ancillary services. When co-locating services is not feasible, proactive linkage via HIV case managers to existing program-funded services is another possible option for increasing access to services.

The findings in this report are subject to at least four limitations. First, these data represent MSM who were in HIV medical care and are not generalizable to MSM not receiving regular medical care or unaware of their HIV infection, among whom unmet needs for services might be more prevalent. Second, service needs were self-reported and not objectively evaluated, and might under- or overestimate unmet needs. Third, prevalence of unmet needs is likely to vary geographically. Local analyses might provide targeted information for resource allocation and policy decisions. Finally, MMP's response rate was suboptimal. Although the data were adjusted to minimize nonresponse bias based on known characteristics of sampled facilities and patients, the possibility of residual nonresponse bias exists.

MSM in HIV medical care have substantial unmet needs for ancillary services, which puts them at risk for health complications and jeopardizes their care and treatment outcomes. The highest prevalences of unmet needs for ancillary services were observed among young MSM and among non-white MSM, the populations with the highest rates of new HIV infection 


\section{Summary}

What is already known about this topic?

Ancillary services, defined as services that support retention in routine human immunodeficiency virus (HIV) medical care and assist with day-to-day living, can improve the health of men living with HIV who have sex with men (MSM) and help them to achieve viral suppression.

What is added by this report?

MSM receiving outpatient HIV medical care during 2013-2014 in the United States reported many unmet needs for ancillary services. Approximately 23\% needed dental care, and 19\% needed eye care. Young, non-Hispanic black, and Hispanic/ Latino MSM had the most unmet needs for ancillary services. The most common reasons for unmet needs were inadequate knowledge or insufficient resources for obtaining services.

What are the implications for public health practice?

Strategies that increase patient awareness of how to obtain ancillary services might improve access to these services, thereby improving the health of MSM living with HIV and reducing age and racial/ethnic disparities in HIV-related health outcomes.

and poor HIV treatment outcomes. Addressing the ancillary service needs of MSM can improve health outcomes and reduce HIV-related health disparities in the United States.

${ }^{1}$ Division HIV/AIDS Prevention, National Center for HIV/AIDS, Viral Hepatitis, STD, and TB Prevention, CDC; ${ }^{2}$ Oak Ridge Institute for Science and Education, Oak Ridge, Tennessee.

Corresponding author: Nicholas P. DeGroote, ndegroote@cdc.gov, 404-639-8375.

\section{References}

1. CDC. HIV surveillance report, 2014, vol. 26. Atlanta, GA: US Department of Health and Human Services, CDC; 2015. http://www.cdc.gov/hiv/pdf/ library/reports/surveillance/cdc-hiv-surveillance-report-us.pdf

2. Conviser R, Pounds MB. The role of ancillary services in client-centred systems of care. AIDS Care 2002;14(Suppl 1):S119-31. http://dx.doi. org/10.1080/09540120220150018

3. CDC. Behavioral and clinical characteristics of persons receiving medical care for HIV infection-Medical Monitoring Project, United States, 2013 Cycle (June 2013-May 2014). HIV surveillance special report 16. Atlanta, GA: US Department of Health and Human Services, CDC; 2016. http://www.cdc. gov/hiv/pdf/library/reports/surveillance/cdc-hiv-hssr-mmp-2013.pdf

4. Bradley H, Viall AH, Wortley PM, Dempsey A, Hauck H, Skarbinski J. Ryan White HIV/AIDS Program assistance and HIV treatment outcomes. Clin Infect Dis 2016;62:90-8. http://dx.doi.org/10.1093/cid/civ708

5. Singh S, Bradley H, Hu X, Skarbinski J, Hall HI, Lansky A. Men living with diagnosed HIV who have sex with men: progress along the continuum of HIV care-United States, 2010. MMWR Morb Mortal Wkly Rep 2014;63:829-33.

6. The White House Office of National AIDS Policy. National HIV/AIDS Strategy for the United States. Washington DC: The White House Office of National AIDS Policy; 2010. https://www.whitehouse.gov/sites/ default/files/uploads/NHAS.pdf

7. Leaver CA, Bargh G, Dunn JR, Hwang SW. The effects of housing status on health-related outcomes in people living with HIV: a systematic review of the literature. AIDS Behav 2007;11(Suppl):85-100. http:// dx.doi.org/10.1007/s10461-007-9246-3

8. Health Resources and Services Administration. Ryan White HIV/AIDS Program annual client-level data report 2014. Washington, DC: US Department of Health and Human Services, Health Resources and Services Administration; 2015.

9. Weiser J, Beer L, Frazier EL, et al. Service delivery and patient outcomes in Ryan White HIV/AIDS Program-funded and nonfunded health care facilities in the United States. JAMA Intern Med 2015;175:1650-9. http://dx.doi.org/10.1001/jamainternmed.2015.4095

10. Beane SN, Culyba RJ, DeMayo M, Armstrong W. Exploring the medical home in Ryan White HIV care settings: a pilot study. J Assoc Nurses AIDS Care 2014;25:191-202. http://dx.doi.org/10.1016/j.jana.2013.10.007 